\title{
A comparative assessment of waste incinerators in the UK
}

\author{
J.D. Nixon ${ }^{a^{*}}$, D.G. Wright ${ }^{b}$, P.K. Dey ${ }^{b}$, S.K. Ghosh ${ }^{c}$ and P.A. Davies ${ }^{a}$ \\ ${ }^{a}$ Sustainable Environment Research Group, School of Engineering and Applied Science \\ Aston University, Aston Triangle, Birmingham, B4 7ET, UK \\ ${ }^{\mathrm{b}}$ Aston Business School, Aston University, Aston Triangle, Birmingham, B4 7ET, UK \\ ${ }^{c}$ Mechanical Engineering Department, Centre for Quality Management System, Jadavpur \\ University, Kolkata 700032, India \\ *corresponding author, e-mail: nixonjd1 @ aston.ac.uk, Tel +44 1212043663
}

\begin{abstract}
The uptake in Europe of Energy from Waste (EfW) incinerator plants has increased rapidly in recent years. In the UK, 25 municipal waste incinerators with energy recovery are now in operation; however, their waste supply chains and business practices vary significantly. With over a hundred more plant developments being considered it is important to establish best business practices for ensuring efficient environmental and operational performance. By reviewing the 25 plants we identify four suitable case study plants to compare technologies (moving grate, fluidised bed and rotary kiln), plant economics and operations. Using data collected from annual reports and through interviews and site visits we provide recommendations for improving the supply chain for waste incinerators and highlight the current issues and challenges faced by the industry. We find that plants using moving grate have a high availability of $87-92 \%$. However, compared to the fluidised bed and rotary kiln, quantities of bottom ash and emissions of hydrogen chloride and carbon monoxide are high. The uptake of integrated recycling practices, combined heat and power, and post incineration non-ferrous metal collections needs to be increased among EfW incinerators in the UK. We conclude that one of the major difficulties encountered by waste facilities is the appropriate selection of technology, capacity, site, waste suppliers and heat consumers. This study will be of particular value to EfW plant developers, government authorities and researchers working within the sector of waste management.
\end{abstract}

Keywords: Energy from Waste (EfW); Municipal Solid Waste (MSW); green supply chains; waste-to-energy; incineration. 


\section{Introduction}

In 2009-10, 49\% of domestic waste in the UK was disposed of by landfill, which represented a fall of $15 \%$ from 2005-06. This reduction in waste sent to landfill is primarily a result of the EU Landfill Directive (1999/31/EC). Under this directive, the UK is obligated to have 35\% of its biodegradable municipal waste produced in 1995 sent to landfill by 2020 (Defra, 2012). In order to meet this target, the UK's landfill tax is increasing rapidly from $28 € /$ tonne in 2007 to $95 € /$ tonne by 2014, where it will remain until 2020 (HM Revenue \& Customs, 2013). However, in comparison to the average European country, landfill rates in the UK are still $12 \%$ higher. Recycling and composting, and incineration rates in the UK are also respectively 4\% and 8\% lower than the EU27 average (Defra, 2011a). In England in 2011, 18\% of MSW was incinerated, 42\% (10.8 million tonnes) was recycled and composted, and 40\% was sent to landfill (Defra, 2011b). In comparison, in 2009, Germany recycled and composted $67.3 \%$, incinerated 31.9\% and landfilled $0.4 \%$ of their MSW, see Figure 1 (Defra, 2011a). After the European Landfill Directive, it was suggested that as many as 170 new incineration plants in the UK could be required to meet the 2020 target (Burnley, 2001). According to Defra (2013), in 2010, there were 73 permitted incinerators in the UK, 18 of which processed MSW. As of May 2013, UKWIN (2013) reported that there were 32 permitted plants to incinerate MSW with an additional 100 potential plants being planned or considered. A significant number of these proposed plants will remain in planning for many years or eventually be cancelled as result of strong opposition from communities and environmentalists. Objections arise from concerns over health risks from emissions, visual impact, noise, traffic and the perception that incineration is detrimental to recycling and waste prevention efforts (Snary, 2002). Many of these issues are faced by all biomass energy developments in the UK (Upreti, 2004).

The characterisation of emissions and the treatment of Air Pollution Control (APC) residues from waste incinerators have been the focus of many researchers (Amutha Rani et al., 2008; Porteous, 2001; Sam-Cwan et al., 2001). Incinerators in Europe today operate under strict emission regulations and state of the art technologies have radically reduced harmful emissions in comparison to those produced in the early 1990s (Porteous, 2001). It has even been reported that under certain conditions the incineration of waste can reduce green house gas emissions (Papageorgiou et al., 2009). Research has also shown that the health risks from waste incineration are five times lower in comparison to landfill (Moy et al., 2008). APC residues, which include fly ash, carbon, lime and dioxins and furans, are one of the main 
drawbacks of incineration as they are hazardous wastes. APC residues in the UK are typically disposed of by hazardous landfill, stored in salt mines or used for acid waste neutralisation.

Bottom ash is the other main waste output from waste incinerators. Once left for a month to stabilise leachates, bottom ash is considered to be environmentally safe (although continual checks are required) and can be used in road, pavement and building construction or similar (Forteza et al., 2004). Considerable amounts of ferrous and non-ferrous metals can be recovered from bottom ash. It has been reported that bottom ash from a dry extraction process, rather than a typical wet extraction process, for a plant in Switzerland on average contains $11 \%$ iron, $2.2 \%$ aluminium, 0.5 copper and $0.003 \%$ gold (Sigg, 2012). In the UK, $5 \%$ of MSW is ferrous and non-ferrous metals.

As demonstrated by countries such as Germany (Figure 1), the incineration of waste does not have to impede recycling. Only $39 \%$ of MSW in the UK is recyclable materials (paper, plastics and glass) (Burnley, 2007). Thus, there is still a large amount of waste to be processed and metals can still be recovered after incineration. However, many difficult decisions need to be made during the planning phase of EfW plants to maintain an efficient green supply chain. The waste supply chain includes collection, storage, delivery, recycling, re-use, processing, post recycling, and ash and APC residue handling. Plants can also choose to utilise Combined Heat and Power (CHP) to improve efficiencies, however difficulties can occur regarding project financing due to ensuring a reliable demand for heat (DECC, 2012). CHP systems requiring a district heating network in the UK also suffer from high retrofitting costs (Enviros, 2008), consumer distrust, unwillingness to sign long off-take contracts (NNFCC, 2012) and lenghty return on investment (ElementEnergy, 2011). Issues can also arise as waste characteristics and generation rates can vary annually, seasonally and in different locations.

The supply chains for waste incinerators in the UK and elsewhere are complex indeed. Approaches for managing each stage of the waste supply chain vary and it is therefore important to fully understand all the upstream and downstream activities for incinerators. As waste generation rates increase, more incinerators will come online; thus there is a need for establishing the best practices for operating incinerators before significant investments in infrastructure are made. This will increase revenues, waste prevention, re-use and recycling, minimise waste volume and mass, reduce landfill rates and alleviate social concerns. It is 
therefore surprising that, to the authors' knowledge, no assessment or comparison of MSW supply chains for waste incinerators in the UK or elsewhere has been carried out. Previous research has had a tendency to focus on specific stages of the supply chain for waste incinerators, such as residues and emissions (Nzihou et al., 2012; Van Gerven et al., 2005), rather than taking a holistic approach. To a further extent, this applies to the broader area of waste biomass supply chain management (Iakovou et al., 2010).

This study aims to determine the best practices across the entire supply chain for EfW incinerators in the UK and elsewhere to ensure efficient environmental and operational performance. In order to achieve this, the technical, financial and operational aspects of different waste incinerators in the UK are to be evaluated and compared. Another specific objective is to identify the main issues and challenges faced by the industry and subsequently provide recommendations for further research. The following section outlines the methodology adopted to meet these objectives. Section 3 examines MSW incinerators with energy recovery throughout the UK and describes four selected case study plants. Data gathered on the four plants is provided in Section 4. Section 5 compares and discusses the findings on each plant and the paper concludes by recommending several best practices for EfW plants.

\section{Methodology}

Firstly, we review 25 operational EfW facilities incinerating MSW in the UK. Subsequently we identify four alternative incineration facilities as suitable case studies: SELCHP, London; Allington Quarry Waste Management Facility, Kent; Tyseley, Birmingham; and NewLincs, Stallingborough. These plants have been chosen as they provide a wide-ranging overview of the alternative methods of waste incinerator operations. Secondly, technical, financial and operational data on each facility have been collected from annual performance reports, during site visits and through structured interviews with plant managers and operators. Collected information includes the plants' capacities, financing, business operations, waste supply chains and issues and challenges. The questionnaire used to structure the interviews can be found in the supplementary online annex. Further information on the extended waste supply chains (household collections to APC residue disposal) has then been gathered during site visits. Thirdly, the findings for the four case studies are summarised and the practices that have been adopted for deploying and operating the plants are compared. Based on the technical, financial and operational data for the alternative plants, their supply chains are 
evaluated to enable conclusions to be drawn on the best practices for waste incinerators in the UK and elsewhere. Recommendations are also provided for further research needed to improve the operations management of EfW facilities.

\section{Case studies}

In accordance with Article 12(2) of the Waste Incineration Directive (2000/76/EC), operators of waste incinerator facilities are required to provide a publically available annual report on the functioning and monitoring of their plant to the UK Environment Agency (2013). Using these reports to review waste incinerators in the UK reveals that, as of May 2013, there are 25 operational incinerators recovering energy from MSW in the UK. Their capacities range from 29,000 to 750,000 tonnes of MSW per annum (tpa), and that 23 utilise moving grate technology, 1 is based on the rotary kiln and 1 uses a fluidised bed (see Table 1). Four case study plants have been subsequently identified that provide a suitable overview of these plants in the UK as they vary in capacity (56 - 500 thousand tonnes of MSW per annum), technology (moving grate, fluidised bed, rotary-kiln), location (urban - rural), financing (merchant plant, private finance initiative) and processes for waste management in general.

1. SELCHP (South East London Combined Heat and Power Ltd) is an energy recovery facility opened in 1994 and receives a total of 420,000 tonnes of MSW per year from the London boroughs of Lewisham, Greenwich, City of Westminster, Bromley, and Southwark, and the Greater London area. SELCHP is also operated by Veolia Environmental Services, a worldwide company specialising in the management of waste. London's MSW generation rate is estimated at around 6 million tpa (SELCHP, 2012).

2. Allington Quarry Waste Management Facility is located in Kent and has been operated by Kent Enviropower Ltd since 2008. The facility can receive up to 500,000 tonnes of non-hazardous waste per year and 80,000 tonnes of recycled waste to be sorted. In 2008/09, households in Kent were estimated to generate over 750,000 tonnes of MSW per annum (Kent Enviropower Ltd, 2012b).

3. Tyseley Energy Recovery Facility handles MSW and hazardous waste from the city of Birmingham. The plant is operated by Veolia Environmental Services and receives 350,000 tonnes of MSW per annum.

4. NewLincs Integrated Waste Management Facility is a small plant that has been operated by NewLincs Developments Ltd since 2003. The facility receives 56,000 tonnes of MSW deliveries a year from North East Lincolnshire council. The plant also 
receives recycled waste and green waste which is processed and sent on to recycling centres and a composting facility (NewLincs, 2013).

\section{Data collection}

The following data have been gathered for the aforementioned facilities during site visits, interviews with plant managers and operators, and from plant annual reports acquired from the UK Environment Agency. The collected information (shown in Table 2) has been categorised as technical (technology, issues and challenges), financial (capital and maintenance costs) and operational (stages of the waste supply chain), and provides an overview of the situation and practices of waste incineration plants in the UK. Table 3 compares emissions recorded from the four plants and Table 4 provides a summary of the plants' key facts.

\section{Outputs of comparative study and discussion}

The technical, financial and operational aspects for the four case study plants are now compared and discussed. With respect to maintaining a green waste supply chain and efficient operational performance, the advantages and disadvantages of different practices are identified.

\section{$5.1 \quad$ Technical}

Three alternative technologies are utilised for incinerating MSW: moving grate (SELCHP and Tyseley), fluidised bed (Allington) and rotary-kiln (NewLincs). The moving grate is the most widely adopted technology for MSW incineration in the UK (see Table 1). Waste is passed through a combustion chamber on grates with air being supplied from beneath to regulate combustion. Start-up time, parasitic loads, availability (annual period of operation at full load) and quantity of bottom ash as a percentage of the MSW input for the SELCHP and Tyseley plants are around 10 hours, $10 \%, 90-95 \%$ and $21-22 \%$ respectively. Where the parasitic load, given in this report as a percentage, is the proportion of generated electricity used for the plants auxiliary power requirements and therefore not exported. The fluidised bed consists of a hot sandbed and benefits of the technology include a compact furnace, versatility, ease of control and high combustion efficiency. However, bed agglomeration is particularly problematic for biomass fired fluidised beds which can result in low plant availability (Skrivfars et al., 2000; Yan et al., 2005). If plant shutdowns occur MSW has to be sent to nearby landfill sites. The fluidised bed technology also requires MSW to be shredded, 
which consumes a large amount of energy - evidenced by Allington's 21\% parasitic loads. Allington demonstrates that the fluidised bed produces a low amount of bottom ash, only $10 \%$ of the MSW input. The rotary-kiln is a large oscillating drum, inclined to assist movement of combusting MSW. The kiln technology is limited to a capacity range of 4000 to 90,000 tonnes per annum, thus it is suited to small scale applications such as NewLincs. The plant availability of NewLincs is comparable to SELCHP and Tyseley (approximately 90\%), however, quantities of bottom ash are lower at only $16 \%$ of the MSW input and parasitic loads are higher at $15 \%$. Other plants adopting the rotary kiln technology have struggled with obtaining a high availability due to the kiln's complex mechanical equipment. Fawley High Temperature Incinerator, Hampshire, UK, uses a kiln to primarily dispose of hazardous waste. In 2008 , they reported an availability of only $43 \%$, however this increased to $72 \%$ in 2011; shutdowns occurred from deslagging, quench throat clearing and feed screw, bearing, roller and other kiln repairs (Pyros Environmental Ltd, 2008; Tradebe Fawley Ltd, 2011).

Some common technical issues and challenges occur for waste incineration plants. Maintaining a constant boiler temperature can be difficult as a result of fluctuating MSW calorific values and moisture contents. The incineration of volatile matters cannot also not always be avoided. Boiler tube ruptures are particularly problematic as accelerated corrosion occurs due to damage from molten ash and flame impingement. Other issues include blockages from bulky items, damaged refractory linings and fluctuating combustion chamber pressures (Shu and Swire, 2004). Thus a number of improvements are still required in plant design to avoid plant downtime. The fluidised bed technology also requires improvements for its application to MSW incineration and shredding should be avoided. Assuming an MSW energy content of $10 \mathrm{MJ} / \mathrm{kg}$ it can be determined that NewLincs has the highest net conversion efficiency of $31 \%$. This is to be expected as a result of the CHP setup. Although Allington's MSW to electricity efficiency is the highest at $27 \%$, the net efficiency is significantly reduced to $21 \%$. SELCHP and Tyseley's net electrical efficiencies are higher at approximately $24 \%$.

The flue gas and water treatment processes and technologies adopted by the case study plants and other waste incinerators are relatively similar. Flue gas is re-circulated in the combustion chamber to reduce emissions of nitrogen oxides (NOx) and help maintain bed temperature. Urea and/or ammonia are also added to the furnace to control NOx emissions. Carbon monoxide and organic carbon emissions can be regulated via the combustion controls. Flue 
gases then leave the combustion chamber and pass through electrostatic precipitators to separate residual ash. Depending on whether a dry or semi-dry gas scrubbing system is implemented, hydrated lime or lime milk is injected into the cleaning system to remove sulphur dioxide and hydrogen chloride. Activated carbon is also injected to absorb dioxins and furans, Polychlorinated Biphenyls (PCBs), mercury and other heavy metals. The final stage is a bag filter system which comprises a large number of tubular filter bags to separate particulate matter and dust. The cleaned gas then exits via a flue chimney(s) and conveyors are used to remove the APC residues. The gas scrubbing process does not result in a liquid effluent; however, demineralised water is required for plant operation due to boiler blowdown losses. Effluent water is passed through a caustic soda scrubber and sodium hydroxide and hydrochloric acid is used for ion exchange resin regeneration. Discharged effluent to sewerage system is monitored to ensure contamination levels remain below limits specified by the local water company.

Continuously monitored gaseous emissions from waste incinerators include sulphur dioxide and hydrogen chloride, carbon monoxide and organic carbon, particulate matter and dust, and oxides of nitrogen. Periodically measured emissions include dioxins and furans, PCBs and mercury. Table 3 shows these key emissions, represented as a percentage of the emission limits. The emissions of nitrogen oxides (NOx) are the highest at all the plants with up to $90 \%$ of the limit being reached at SELCHP. Allington achieves significantly lower NOx emissions with 59\%. Except for carbon monoxide (CO), Allington has the lowest emissions for all continuously monitored variables. However, Allington produces far more APC residues than the other plants $-9 \%$ of the MSW input. Interestingly, NewLincs has significantly lower $\mathrm{CO}$ and dioxin and furan emissions with only $6 \%$ and $3 \%$ respectively of the limit being reached. Periodically measured emissions of other metals and non-metals are available from: (Kent Enviropower Ltd, 2012a; NewLincs, 2012; SELCHP, 2012; Veolia, 2013a).

Emissions from waste incinerators pose a serious concern to human health and the environment. Particulate matter can cause a range of respiratory problems. Dioxins, furans and PCBs are carcinogenic. And mercury, along with other heavy metals, is toxic. The Green House Gases (GHG) emitted in the flue gas from waste incinerators are significant and estimates for carbon dioxide $\left(\mathrm{CO}_{2}\right)$ emissions are in the region of $0.5 \mathrm{kgCO}_{2} / \mathrm{kWh}$. However, the quantity of $\mathrm{CO}_{2}$ and other emissions emitted during combustion of MSW is highly 
dependent on the composition of waste. Calabrò (2009) investigates the effects of alternative MSW separation methods on $\mathrm{CO}_{2}$ emissions and energy content. He found that although non separation of plastics increase energy content, the potential increase in energy production will not offset the increase in GHG emissions released from waste incinerators. Therefore he concludes that plastics must be separated and recycled from MSW before incineration to reduce GHG emissions and that overall an increase in separation rates will reduce GHG emissions. Given incinerators' relatively high levels of $\mathrm{CO}_{2}$ and other GHG emissions, energy recovery plays an important role to mitigate their environmental impact and therefore incineration without energy recovery should not be practiced other than in special cases (Astrup et al., 2009). Calabrò (2010) further researched the effects of waste separation on MSW finding that (i) separating organics and recycles has a negligible effect of the Lower Heating Value (LHV), (ii) separating organics and recyclables, except plastics, increases LHV and, (iii) separating recyclables only (no organics) rapidly decreases LHV.

\subsection{Financial}

The plant economics for the four case studies are comparable. The capital costs for the plants range from approximately $3.5-4$ million $€ / \mathrm{MW}$ (electrical and thermal). The majority of revenue is generated from gate fees, which are related to the UK's landfill tax (currently 85 $€ /$ tonne, increasing to $95 € /$ tonne by 2014), with exported electricity (and heat in the case of NewLincs) an additional benefit. One of the case study plants reported that they even sometimes reject high plastic and energy content wastes, or charge a premium gate fee, as they can then not burn as much waste with a lower calorific value. Small additional quantities of commercially sensitive trade wastes (around 5\%) are also disposed of at the plants for a high gate fee. Hazardous waste is also processed at Tyseley for a high gate fee.

Financing of EfW facilities is complicated, but they are typically private finance initiatives (PFI). However, SELCHP is a merchant plant operated by Veolia Environmental Services and SELCHP whom will retain ownership after 25 years. Operating costs for the emission cleaning systems are the major expense for EfW plants and can range from 5 to $17 € /$ tonne of MSW incinerated (Kedrowski et al., 2010). This is a concern as expensive scrubber systems may not be implemented in countries that do not conform to strict EU emission regulations or similar. 
Revenue from recycling has increased dramatically in recent years. In Europe, between 2000 and 2010, the price of waste paper and board has increased from approximately 100 to 150 $€ /$ tonne and glass waste has increased from 37 to $50 € /$ tonne. The value of waste plastic has been quite variable. In 2009 the price crashed from $375 € /$ tonne to $230 € /$ tonne. By the end of 2010 the value of plastic had increased back up to $300 € /$ tonne (European Commission Eurostat, 2013). Older plants such as SELCHP and Tyseley only perform post incineration recycling of large scrap and ferrous metals which do not currently count towards the UK's recycling targets and significant quantities of non ferrous metals can be still obtained from bottom ash. Allington adopts the most integrated modern system for recycling, separating and baling alternative materials and carrying out pre and post incineration ferrous and non ferrous metal collections. Significant revenues were reported by Allington and Newlincs as a result of their integrated approach to waste incineration and recycling. This approach also avoids separate waste handling facilities, improving transportation logistics and maximising recycling efforts.

\subsection{Operational}

There are a number of differences among how EfW incinerators are operated in the UK. Figure $2 \mathrm{a}-\mathrm{d}$ outlines the supply chains for the four case study plants and highlights the alternative methods that have been adopted for carrying out waste deliveries, separation, storage, incineration, recycling and re-use. In particular, the approaches utilised for recycling and the stages at which recycling are performed vary significantly. SELCHP is one of the oldest incinerators in the UK. It receives unsorted waste, and un-recyclable waste from a sorting facility in Southwark. SELCHP only collects ferrous metals after incineration with bottom ash further processed for metal recovery at a separate site. Tyseley also receives unsorted waste which is passed straight into the incinerator with ferrous metals then collected afterwards. Allington is an integrated incinerator and sorting plant, receiving kerbside collected recyclables for sorting and unsorted MSW. Un-recyclable materials and MSW are shredded and ferrous and non-ferrous metals are removed before and after incineration. As a result of NewLincs' small scale, investment in equipment for non-ferrous metal collections has not been made. Recyclables delivered to NewLincs are stored and handled before being transported to recycling centres for sorting and processing. Green waste is also received and shredded at NewLincs before onwards transportation to a nearby composting plant. 
The majority of uncertainties in the supply chain for EfW incinerators arise from the waste deliveries. Delivery times need to be carefully managed in order to achieve a uniformed delivery of waste throughout the day. This is particularly challenging for plants located in central city locations. To improve traffic and load logistics at the Tyseley plant, night time deliveries are made (half of the total MSW collected) from two transfer stations. This also enables waste to be bulked before being transported and increases vehicle capacity from 8 tonnes to 25 tonnes, further reducing traffic congestion (Veolia, 2013b). Another uncertainty for incinerators is the energy content of delivered MSW, which is gradually increasing as recycling efforts improve. The quantity of waste being delivered is also variable and changes with season. The quantity of waste supplied to Allington is a particular uncertainty in their supply chain. Whilst they are contracted to receive 325,000 tpa from Kent County Council they also have the capacity to receive an additional 175,000 tpa of waste through short term contracts. In 2012, Allington incinerated 423,000 tonnes of MSW and processed only 27,400 tonnes of recyclables, which is well below their capacity (Kent Enviropower Ltd., 2012c).

Only a few waste incinerators in the UK utilise CHP to export both electricity and heat. SELCHP, Tyseley and Allington only supply electricity to the UK's national grid. The SELCHP plant was initially designed for exporting heat to a network, but as of yet this has not been implemented. However, plans have been approved for the development of a heat network between SELCHP and residential estates in Southwark (Southwark Council, 2013). NewLincs supplies electricity and heat to a neighbouring chemical factory and have a grid connection in place as a backup. However, the demand for heat in the NewLincs area has reduced significantly from when the plant was first commissioned. In 2012 they exported only $1400 \mathrm{MWh}_{\text {thermal }}$ out of a possible $17000 \mathrm{MWh}_{\text {thermal }}$. NewLincs is not the only EfW plant that has not been able to maximise their heat export capabilities in the UK. Sheffield, UK, Energy Recovery Facility utilises a Community District Energy network that can export up to $60 \mathrm{MW}_{\text {thermal }}$ as well as exporting $19 \mathrm{MW}$ of electrical power to the National Grid. However, in 2011, the plant only exported $19 \%$ of its heat capacity; $11.2 \mathrm{MW}_{\text {thermal }}(98,130$ MWh) (Veolia Sheffield ES Ltd., 2011).

CHP is vastly underutilised in the UK and therefore there is a need for growth in this area and projects should take advantage of the current Renewable Obligation Certificate (ROC) scheme (EfW with CHP receives 1 ROC/MWh) (DECC, 2013). However, the reviewed plants highlight that the successful uptake of CHP is difficult even when it is considered at 
the initial project planning and site selection phase. Nevertheless, the economic feasibility of incinerators relies on the landfill tax, rather than sales of heat and power. This emphasises the need for the landfill tax or similar to be adopted and considered by policymakers and other key decision makers in developing countries to enable alternative cleaner waste management schemes to become economically feasible. Small-scale EfW schemes, such as NewLincs, can be decentralised and located in the proximity of large heat users. This greatly increases the efficiency of an EfW plant and may be a more acceptable solution to waste management by adhering to the 'proximity principle' of treating waste close to where it is produced. At the kiln's smallest scale (4000 tpa) the use of a steam turbine is impractical, however generated heat can be used for alternative applications (industrial heat, cooling, etc.).

Issues often arise in energy project development relating to the appropriate selection of technology, capacity, location, suppliers and customers, and this is evident for the four case studies. SELCHP has yet to implement CHP. Allington utilises a fluidised bed that is likely to cause difficulties regarding reliability. Tyseley is located near many industries and residential areas and thus could be well suited for CHP. NewLincs is currently unable to maximise their use of CHP due to a lack of demand in the vicinity. However, it is worth noting that NewLincs benefited from an extremely quick commissioning time as a result of its small scale, as did Tyseley with the site location being a previous incineration site.

To rationalise technology, application and other waste management strategy choices, decision analysis tools or similar should be adopted. A range of structured Multi-Criteria DecisionMaking (MCDM) methods have been adopted by a number of authors working in the field of waste management (Pires et al., 2011). Kontos et al. (2005) used the Analytical Hierarchy Process (AHP) and Sharifi et al. (2009) used a Geographical Information System (GIS) for landfill site selection. Contreras et al. (2008) also used AHP to select an integrated waste management scheme for Boston, USA. Minciardi et al. (2008) proposed a multi-objective decision making method for MSW flow optimisation for the municipality of Genova, Italy. And we have used the Analytical Network Process (ANP) to select a technology for recoverying energy from waste in India (Nixon et al., 2013). Regarding supply chain optimisation for bioenergy facilities, several authors have used mixed integer programming and goal programming techniques (Scott et al., 2012). MCDM methods for waste incinerator project planning will be particularly valuable as they enable a holistic approach to be taken to decision making, thus all the conflicting technical, financial, environmental and social criteria 
can be incorporated into the decision rationale. While a number of decision support tools have been developed for use by local authorities, non-governmental organisations and academia (Winkler and Bilitewski, 2007), we believe that their uptake needs to be increased and the application of MCDM tools for technology selection and supply chain optimisation is an area worthy of further research. Future studies can build upon the variables and objective data presented in this study, which will further facilitate the implementation of best practices for waste facilities to maximise operational and environmental performance.

\section{Conclusion}

The research aim to determine best practices for EfW incinerators has been primarily achieved through reviewing 25 operational plants and a detailed analysis of four case study plants in the UK. The case studies demonstrate a growing maturity in the industry and a development of best practices arising, however, further efforts need to be made to improve and standardise the integration of waste supply chains into existing EfW facilities and those in planning. Furthermore, combined heat and power is vastly underutilised in the UK with only 3 out of the 25 plants currently exporting heat and even these plant are not maximising their heat export capacity. We find that the moving grate technology is the most widely adopted and reliable technology for energy recovery from waste, however, the fluidised bed reduces quantities of bottom ash and the rotary kiln is particularly suitable for small scale solutions for treating waste near to where it is produced. Having analysed the four plants and reviewed the literature, the following current best practices are identified:

1. Integrate waste incinerators with recycling facilities and composting plants to reduce GHG emissions, improve transportation logistics and increase profits.

2. Perform pre and post incineration metal collections to gather valuable ferrous and non-ferrous metals, including: aluminium, copper and gold.

3. Use storage facilities in large cities to improve transportation logistics and reduce traffic volume.

4. Utilise combined heat and power effectively to increase conversion efficiencies and revenue.

5. Use decision support systems during plant development to assist decision makers and facilitate communication between authorities and plant operators.

EfW plants will continue to be commissioned to handle waste and support the UK in achieving the forthcoming 2020 target. The authors therefore consider that this study will 
provide valuable data for future research and will inform academics, plant operators, authorities and other stakeholders on the best practices for waste incineration. Further research is required to develop a generalised model for specifying standard practices for waste integration and management.

\section{Acknowledgements}

The authors would like to acknowledge the assistance from South East London Combined Heat and Power Ltd. (SELCHP), Kent Enviropower Ltd. (Allington Quarry Waste Management Facility), Veolia Environmental Services (SELCHP and Tyseley Energy Recovery Facility) and NewLincs Developments Ltd. We would also like to acknowledge the support from the Royal Academy of Engineering, in the form of a Distinguished Visitor's Fellowship for S.K. Ghosh and funding from the British Council under a UKIERI UGC Thematic Partnership.

\section{Figures and tables}

Figure 1: Disposal treatment of municipal solid waste in Europe (Defra, 2011a).

Figure 2a-d: The supply chains for the SELCHP, Allington, Tyseley and NewLincs energy from waste incineration plants.

Table 1: Operational MSW incinerators with energy recovery in the UK. Plants that are under construction, incinerators without energy recovery and gasification incinerators are excluded.

Table 2: A technical, financial and environmental comparison of four waste incinerators in the UK; SELCHP, Allington, Tyseley and NewLincs.

Table 3: Emissions as a percentage of emission limits (Defra, 2010) from SELCHP, Allington, Tyseley and Newlincs, taken from: (Brown, 2000; Kent Enviropower Ltd, 2012a; NewLincs, 2012; SELCHP, 2012; Veolia, 2007, 2013a) and contains environment agency information (C) Environment Agency and database right.

Table 4: Summary of key facts.

\section{References}

Amutha Rani, D., Boccaccini, A.R., Deegan, D., Cheeseman, C.R., 2008. Air pollution control residues from waste incineration: Current UK situation and assessment of alternative technologies. Waste Management 28, 2279-2292. 
Astrup, T., Møller, J., Fruergaard, T., 2009. Incineration and co-combustion of waste: accounting of greenhouse gases and global warming contributions. Waste Management \& Research 27, 789-799.

Brown, R.S., 2000. Report on Air Quality in the Vicinity of the South East London Combined Heat \& Power Facility.

Burnley, S., 2001. The impact of the European landfill directive on waste management in the United Kingdom. Resources, Conservation and Recycling 32, 349-358.

Burnley, S.J., 2007. A review of municipal solid waste composition in the United Kingdom. Waste Management 27, 1274-1285.

Calabrò, P.S., 2009. Greenhouse gases emission from municipal waste management: The role of separate collection. Waste Management 29, 2178-2187.

Calabrò, P.S., 2010. The effect of separate collection of municipal solid waste on the lower calorific value of the residual waste. Waste Management \& Research 28, 754-758.

Contreras, F., Hanaki, K., Aramaki, T., Connors, S., 2008. Application of analytical hierarchy process to analyze stakeholders preferences for municipal solid waste management plans,

Boston, USA. Resources, Conservation and Recycling 52, 979-991.

Council Directive (EC), DIRECTIVE 1999/31/EC of 26 April 1999, L 182/1. Official Journal of the European Communities.

Council Directive (EC), DIRECTIVE 2000/76/EC of 4 December 2000, L 332/91. Official Journal of the European Communities.

DECC, 2012. The Future of Heating: A strategic framework for low carbon heat in the UK, Department of Energy \& Climate Change.

DECC, 2013. Renewable Obligation Certificate (ROC) Banding, Department of Energy and Climate Change.

Defra, 2010. Environmental Permitting Guidance, The Waste Incineration Directive Defra, 2011a. Environmental Statistics - Key Facts. Accessed $21^{\text {st }}$ January 2013, Available from: www.defra.gov.uk/statistics/files/Environmental-key-statistics-Dec-2011.pdf Defra, 2011b. Government Review of Waste Policy in England 2011.

Defra, 2012. Landfill Allowance Trading Scheme. Accessed $11^{\text {th }}$ February 2012, Available from: www.defra.gov.uk/environment/waste/local-authorities/landfill-scheme

Defra, 2013. Incineration of Municipal Solid Waste, February 2013.

ElementEnergy, 2011. Achieving Deployment of Renewable Heat, Element Energy Limited, Cambridge.

Environment Agency, 2013. 
Enviros, 2008. Barriers to Renewable Heat: Executive Summary. Enviros Consulting Limited, London.

European Commission Eurostat, 2013. Recycling - secondary material price indicator.

Forteza, R., Far, M., Seguí, C., Cerda, V., 2004. Characterization of bottom ash in municipal solid waste incinerators for its use in road base. Waste Management 24, 899-909.

HM Revenue \& Customs, 2013. A general guide to Landfill Tax. Accessed $21^{\text {st }}$ January 2013, Available from:

http://customs.hmrc.gov.uk/channelsPortalWebApp/channelsPortalWebApp.portal?_nfpb=tru e\&_pageLabel=pageExcise_ShowContent\&propertyType=document\&id=HMCE_CL_00050 9\#P310_23536

Iakovou, E., Karagiannidis, A., Vlachos, D., Toka, A., Malamakis, A., 2010. Waste biomassto-energy supply chain management: A critical synthesis. Waste Management 30, 1860-1870. Kedrowski, C., Hug, D., Frey, R., Kaspar, A., 2010. Comparison of Acid Gas Control Technologies in EFW Facilities. ASME.

Kent Enviropower Ltd, 2012a. Allington Monthly Emission Data: October 2012. Kent Enviropower Ltd, 2012b. The Allington Quarry Waste Management Facility. Kontos, T.D., Komilis, D.P., Halvadakis, C.P., 2005. Siting MSW landfills with a spatial multiple criteria analysis methodology. Waste Management 25, 818-832.

Minciardi, R., Paolucci, M., Robba, M., Sacile, R., 2008. Multi-objective optimization of solid waste flows: Environmentally sustainable strategies for municipalities. Waste Management 28, 2202-2212.

Moy, P., Krishnan, N., Ulloa, P., Cohen, S., Brandt-Rauf, P.W., 2008. Options for management of municipal solid waste in New York City: A preliminary comparison of health risks and policy implications. Journal of environmental management 87, 73-79.

NewLincs, 2012. Newlincs Development Ltd, Annual WID Report.

NewLincs, 2013. Newlincs Development Ltd. Accessed $28^{\text {th }}$ January 2013, Available from: www.newlincs.com

Nixon, J.D., Dey, P.K., Ghosh, S.K., Davies, P.A., 2013. Evaluation of options for energy recovery from municipal solid waste in India using the hierarchical analytical network process. Energy, http://dx.doi.org/10.1016/j.energy.2013.06.052.

NNFCC, 2012. NNFCC Barriers to Bioenergy Matrix, A report for DECC. National NonFood Crops Centre, York.

Nzihou, A., Themelis, N.J., Kemiha, M., Benhamou, Y., 2012. Dioxin emissions from municipal solid waste incinerators (MSWIs) in France. Waste Management 32, 2273-2277. 
Papageorgiou, A., Barton, J.R., Karagiannidis, A., 2009. Assessment of the greenhouse effect impact of technologies used for energy recovery from municipal waste: A case for England. Journal of environmental management 90, 2999-3012.

Pires, A., Martinho, G., Chang, N.-B., 2011. Solid waste management in European countries: A review of systems analysis techniques. Journal of environmental management 92, 10331050 .

Porteous, A., 2001. Energy from waste incineration — a state of the art emissions review with an emphasis on public acceptability. Applied Energy 70, 157-167. Pyros Environmental Ltd, 2008. Annual performance report for Pyros Environmental Ltd. Sam-Cwan, K., Hwan, J.S., Il-Rok, J., Ki-Hun, K., Myung-Hee, K., Jae-Hyung, K., JunHeung, Y., Seung-Jin, K., Jae-Cheon, Y., Dong-Hee, J., 2001. Removal efficiencies of PCDDs/PCDFs by air pollution control devices in municipal solid waste incinerators. Chemosphere 43, 773-776.

Scott, J.A., Ho, W., Dey, P.K., 2012. A review of multi-criteria decision-making methods for bioenergy systems. Energy 42, 146-156.

SELCHP, 2012. SELCHP Energy Recovery Facility.

Sharifi, M., Hadidi, M., Vessali, E., Mosstafakhani, P., Taheri, K., Shahoie, S., Khodamoradpour, M., 2009. Integrating multi-criteria decision analysis for a GIS-based hazardous waste landfill sitting in Kurdistan Province, western Iran. Waste Management 29, 2740-2758.

Shu, A., Swire, S., 2004. Technical challenges and abatements of a mass burn waste-toenergy plant co incinerating municipal solid waste and industrial waste. ASME.

Sigg, F., 2012. EfW - An important step towards Zero Waste (nothing is non recyclable) incinerator bottom ash, available technologies and how it is handled in different countries, Recycling and Waste Management (RWM), Birmingham, UK.

Skrivfars, B.-J., Zevenhoven, M., Backman, R., Öhman, M., Nordin, A., 2000. Effect of fuel quality on the bed agglomeration tendency in a biomass fired fluidised bed boiler.

Snary, C., 2002. Risk Communication and the Waste-to-energy Incinerator Environmental Impact Assessment Process: A UK Case Study of Public Involvement. Journal of Environmental Planning and Management 45, 267-283.

Southwark Council, 2013. Gateway 2: Contract Award Approval - Southwark Heat Network from South East London Combined Heat and Power Plan (SELCHP) - Additional Services Contract.

Tradebe Fawley Ltd, 2011. Annual performance report for Tradebe Fawley Ltd. 
UKWIN, 2013. Map of Potential, Existing and Prevented Incinerators, Municipal Waste Incinerators, May 2013.

Upreti, B.R., 2004. Conflict over biomass energy development in the United Kingdom: some observations and lessons from England and Wales. Energy Policy 32, 785-800.

Van Gerven, T., Geysen, D., Stoffels, L., Jaspers, M., Wauters, G., Vandecasteele, C., 2005. Management of incinerator residues in Flanders (Belgium) and in neighbouring countries. A comparison. Waste Management 25, 75-87.

Veolia, 2007. Tyseley Annual Performance Report.

Veolia, 2013a. Emissions to air data.

Veolia, 2013b. Trasfer stations. Accessed $21^{\text {st }}$ January 2013, Available from:

www.veoliaenvironmentalservices.co.uk/Birmingham/Facilities/Transfer-stations

Veolia Sheffield ES Ltd., 2011. Annual Performance Report, Sheffield Energy Recovery

Facility.

Winkler, J., Bilitewski, B., 2007. Comparative evaluation of life cycle assessment models for solid waste management. Waste Management 27, 1021-1031.

Yan, R., Liang, D.T., Tsen, L., 2005. Case studies-Problem solving in fluidized bed waste fuel incineration. Energy Conversion and Management 46, 1165-1178. 